\title{
Relationship between maximum oxygen uptake and peripheral vasoconstriction in a cold environment
}

\author{
Takafumi Maeda ${ }^{1,2}$ (D)
}

\begin{abstract}
Background: Various individual characteristics affect environmental adaptability of a human. The present study evaluates the relationship between physical fitness and peripheral vasoconstriction in a cold environment.

Methods: Seven healthy male students (aged 22.0 years) participated in this study. Cold exposure tests consisted of supine rest for $60 \mathrm{~min}$ at $28{ }^{\circ} \mathrm{C}$ followed by $90 \mathrm{~min}$ at $10^{\circ} \mathrm{C}$. Rectal and skin temperatures at seven sites, oxygen consumption, and the diameter of a finger vein were measured during the experiment. Metabolic heat production, skin heat conductance, and the rate of vasoconstriction were calculated. Individual maximum oxygen consumption, a direct index of aerobic fitness, was measured on the day following the cold exposure test.

Results: Decreases in temperature of the hand negatively correlated with the changes in rectal temperature. Maximum oxygen consumption and the rate of vasoconstriction are positively correlated. Furthermore, pairs of the following three factors are also significantly correlated: rate of metabolic heat production, skin heat conductance, and the rate of vasoconstriction.

Conclusion: The results of this study suggested that the capacity for peripheral vasoconstriction can be improved by physical exercise. Furthermore, when exposed to a cold environment, fitter individuals could maintain metabolic heat production at the resting metabolic level of a thermoneutral condition, as they correspondingly lost less heat.
\end{abstract}

Keywords: Thermoregulation, Physical fitness, Cross-adaptation, Vasoconstriction, Metabolic heat production, Cold

\section{Introduction}

Human thermoregulatory functions are influenced by various factors, such as genetic factors, season, lifestyles, and individual physical and physiological characteristics [1-4]. Also, aerobic exercise capacity effects thermoregulatory function, and physical endurance training improves thermal adaptability.

Several studies have investigated the effects of physical training on thermoregulation in a hot environment [5-8], and the findings have suggested that physical training improves the capacity for thermoregulation. Many investigators have found improved ability to thermoregulate by cross-adaptation to exerciseinduced hyperthermia, through improvements in and

\footnotetext{
Correspondence: maeda@design.kyushu-u.ac.jp

${ }^{1}$ Department of Human Science, Faculty of Design, Kyushu University, 4-9-1, Shiobaru, Minami-ku, Fukuoka 815-8540, Japan

${ }^{2}$ Physiological Anthropology Research Center, Faculty of Design, Kyushu University, 4-9-1, Shiobaru, Minami-ku, Fukuoka 815-8540, Japan
}

enhancements of vasodilation [5-7] and the sweat response [8].

Regarding thermoregulatory ability in a cold environment, physical endurance training increases cold tolerance, and individuals with higher levels of physical fitness exhibit higher adaptability to cold [9-19]. According to such studies, training increases metabolic heat production in a cold environment, which leads to a better cold tolerance $[9-11,13,15,18]$. However, the effects of aerobic training on the ability to inhibit heat loss in a cold environment are controversial, because studies have indicated that skin temperature in fitter individuals exposed to cold can be either higher [11,20] or lower $[16,19]$.

Previous studies have used skin heat conductance as an index of heat loss, from which the degree of vasoconstriction was estimated [11, 12, 18]. Some investigators have reported that the skin heat conductance of 
relatively fit individuals is greater than that of less-fit individuals during cold exposure and heat loss is more substantial [11, 12]. But others have found lower skin heat conductance and less heat loss among relatively fit individuals exposed to a cold environment when both trained and untrained groups had the same ratio of body fat [18]. Thus, the relationship between physical fitness and cold-induced vasoconstriction determined from skin heat conductance is obscure and probably influenced by body fatness.

Although skin heat conductance is reflected as heat loss and calculated as the differences between the core and skin temperature and between the skin and ambient temperature, it does not directly reflect vasoconstriction. Furthermore, because physical characteristics (particularly subcutaneous fat) affect skin heat conductance, isolating only the effects of physical fitness and/or training is difficult. Thus, vasoconstriction that is an index of cold tolerance cannot be evaluated by skin heat conductance, which also explains neither vasoconstriction nor the mechanisms involved in changes or improvements in physiological adaptability conferred by physical training.

Daanen (2003) in a review of local cold tolerance among humans noted the difficulties in noninvasively and continuously measuring blood vessel diameter as an index of vasoconstriction [21]. However, the vascular diameter can now be measured noninvasively and continuously using near-infrared light in Japan, which used for a clinical investigation [22].

Aerobic training improves the compliance of peripheral blood vessels [23-26], as well as the autonomic nervous function controlling the vasomotor system [27, 28]. Therefore, we considered that peripheral vasoconstriction would be improved by physical training, and thus heat loss would be more inhibited in a cold environment.

We postulated that fitter individuals have better vasoconstriction and better heat loss inhibition in the cold. The present study focused on the peripheral vasomotor system as a key factor involved in the inhibition of heat loss in a cold environment. The first objective was to determine the correlation between physical fitness and the degree of vasoconstriction measured directly on fingers. The second objective was to estimate the effects of aerobic physical fitness on the mechanisms of thermoregulation in the context of a cold environment, and, in particular, to determine the balance between increased metabolic heat production and the inhibition of heat loss.

\section{Methods}

\section{Subjects}

The Ethics Committee of Fukushima Medical University approved the study protocol. The experimental test procedures were explained in detail to various individuals who then provided written informed consent to participate in the study. Seven healthy male students (age 22.0 \pm 1.4 years old) volunteered to participate. All of them were healthy and belong to sports clubs such as soccer, rugby, and aikido which was conducted for $1 \sim 2 \mathrm{~h} /$ day and 2 3 days/week. The physical characteristics of the subjects are given in Table 1 . Body surface area (BSA) was calculated from the height and weight of each participant using a formula adapted for adult Japanese males (Takahira, 1925: $\left[\right.$ BSA $\left.\left(\mathrm{cm}^{2}\right)\right]=[\text { weight }(\mathrm{kg})]^{0.425} \times$ [height $\left.(\mathrm{cm})]^{0.725} \times 72.76\right)$. Body fat $(\%)$ was measured on a scale using the impedance method with four electrodes (TBF-102, Tanita, Japan). Subcutaneous fat thickness was calculated as average skinfold thickness, which was measured with a caliper at the subzygomatic border, hyoid region, breast, side breast, subscapular region, abdomen, lumbar region, front and back thighs, knee, calf, and triceps. We assumed that the whole body subcutaneous fatness is related to finger subcutaneous fat, although we did not measure the finger subcutaneous fat thickness.

\section{Cold exposure test}

Rectal $\left(T_{\text {re }}\right)$ and skin temperatures at the forehead, abdomen, forearm, back of the hand, thigh, shin, and instep were measured at $1 \mathrm{~min}$ intervals using a thermistorthermometer with a data-logger (LT-8, Gram Corp., Japan). The mean skin temperature $\left(\bar{T}_{\text {sk }}\right)$ was calculated from the seven points on the body using a method devised by Hardy and DuBois [29]. The diameter of the blood vessels (DBVs) at the second knuckle of the right middle finger was measured at 5 min intervals during the experiment using near-infrared spectroscopic imaging (Astrim, Sysmex Corp, Japan; Fig. 1). A nearinfrared ray from a light emitting diode was passed through the blood vessels of a finger to hit the lens of a charge-coupled device camera, images from which DBV was calculated (Fig. 1) [22]. Oxygen consumption $\left(\mathrm{V} \cdot \mathrm{O}_{2}\right)$ was measured in a breath-by-breath manner (AE-300S, Minato Medical Science, Japan) during cold exposure.

Table 1 Physical and physiological characteristics of participants

\begin{tabular}{ll}
\hline Characteristics & Mean \pm SD \\
\hline Age (years) & $22.0 \pm 1.53$ \\
Height $(\mathrm{cm})$ & $169.0 \pm 5.20$ \\
Body mass $(\mathrm{kg})$ & $61.7 \pm 7.12$ \\
Body fat $(\%)$ & $16.6 \pm 3.60$ \\
Body mass index $\left(\mathrm{kg} / \mathrm{m}^{2}\right)$ & $21.6 \pm 1.84$ \\
Body surface area $\left(\mathrm{m}^{2}\right)$ & $1.72 \pm 0.11$ \\
Subcutaneous fat thickness $(\mathrm{cm})$ & $0.50 \pm 0.17$ \\
$\mathrm{~V} \cdot \mathrm{O}_{2 \text { max }}(\mathrm{ml} / \mathrm{min} / \mathrm{kg})$ & $52.3 \pm 1.94$ \\
\hline
\end{tabular}



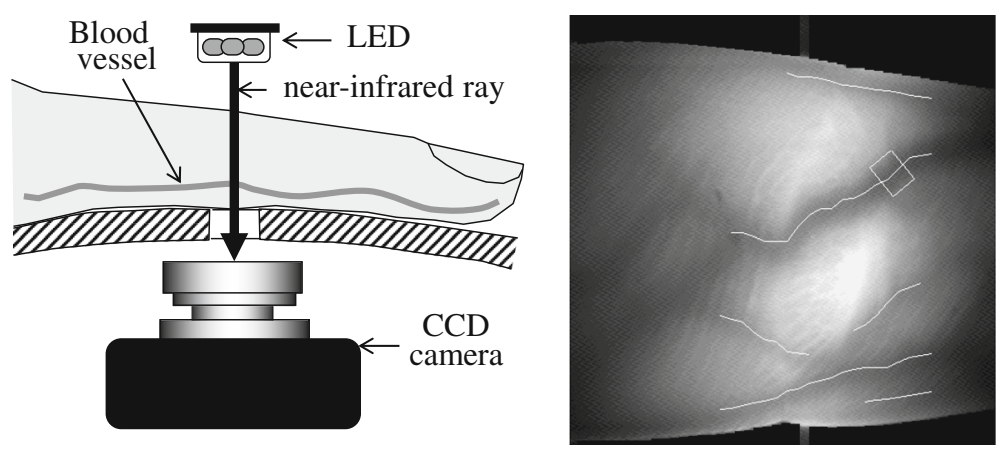

Fig. 1 System for measuring diameter of the finger blood vessels

Temperature sensors were fixed inside the rectum and at seven points on the skin, then a probe unit to measure DBV was fixed on the middle finger of the right hand. The mask for sampling expired gas was fixed on the mouth and nose, and then the participants rested in the supine position for at least $60 \mathrm{~min}$ in a room with ambient temperature and relative humidity maintained at $28{ }^{\circ} \mathrm{C}$ and $50 \%$, respectively. Thereafter, the participants rested in the supine position for $90 \mathrm{~min}$ in a climatic chamber where the temperature and relative humidity were maintained at $10{ }^{\circ} \mathrm{C}$ and $50 \%$, respectively. The subjects wore a short-sleeved cotton T-shirt and short cotton pants ( 0.3 clo).

After the experiment, percent of minimum DBV relative to the baseline (\%DBV) was calculated as the minimum value divided by the baseline value [\%DBV $=($ minimum $\mathrm{DBV}) /($ baseline $\mathrm{DBV}) \times 100]$. The rate of vasoconstriction $(\% \mathrm{VC})$, percent change relative to the baseline, was also calculated using the equation as follows: \%VC $=100-\% \mathrm{DBV}$. $\mathrm{V} \cdot \mathrm{O}_{2}$ was used as an index of metabolic heat production [30], and the change in $\mathrm{V}$. $\mathrm{O}_{2}\left(\% \mathrm{~V} \cdot \mathrm{O}_{2}\right)$ was calculated as the value at $90 \mathrm{~min}$ divided by the baseline value $(0 \mathrm{~min})$. Skin heat conductance $\left(\mathrm{K}_{\mathrm{b}}, \mathrm{W} / \mathrm{m}^{2{ }^{\circ}} \mathrm{C}\right)$ was calculated from the following equation $[11,12,18]$ :

$$
K_{\mathrm{b}}=(R+C) /\left(T_{\mathrm{re}}-\bar{T}_{\mathrm{sk}}\right)
$$

where $(R+C)$ indicates radiant and convective heat exchange (in $\left.\mathrm{W} / \mathrm{m}^{2}\right)$, calculated as $(R+C)=h\left(\bar{T}_{\mathrm{sk}}-\right.$ $\left.T_{\mathrm{db}}\right)$, where $h$ is the combined heat transfer coefficient for radiation and convection with a value of $8.3 \mathrm{~W} / \mathrm{m}^{2}$ 。 $\mathrm{C}$, that was determined as described by Colin et al. [31]. $T_{\text {re, }}, \bar{T}_{\text {sk }}$, and $T_{\mathrm{db}}$ are rectal, mean skin, and dry bulb $\left(10{ }^{\circ} \mathrm{C}\right)$ temperatures, respectively.

\section{Physical fitness test}

Individual maximum oxygen consumption $\left(\mathrm{V} \cdot \mathrm{O}_{2 \max }\right)$ as a direct index of aerobic physical fitness was measured on the day after the cold exposure test to estimate the relationship between physical fitness and the observed findings. Oxygen consumption $\left(\mathrm{V}^{-} \mathrm{O}_{2}\right)$ was calculated in a breath-by-breath manner by ventilation and differences in oxygen concentrations of inspired and expired gases (AE-300S, Minato Medical Science, Japan) during physical exercise on a bicycle ergometer with a continuously incremental workload $(+10 \mathrm{~W} / \mathrm{min})$. The test was terminated upon self-determined exhaustion or when the participant could no longer maintain the $50 \mathrm{rpm}$ cadence. The criteria for achieving $\mathrm{V} \cdot \mathrm{O}_{2 \max }$ included a respiratory gas exchange ratio exceeding 1.0 and visible signs of exhaustion, such as breathlessness and inability to maintain the required power output [12]. In this manner, the relationship between aerobic capacity and physiological responses to cold was estimated.

\section{Statistical analysis}

The body temperature of one participant could not be recorded due to faulty sensors, and the DBV of another could not be recorded because the veins in the fingers were undetectable. Therefore, we analyzed the body temperature and DBV for six participants.

The average value of the last $5 \mathrm{~min}$ at $28{ }^{\circ} \mathrm{C}$ was used as the baseline value, and the average value for 88 to 90 min during cold exposure was used as the value at $90 \mathrm{~min}$. The volume $(\Delta)$ and rate of change (\%) from the baseline value were also calculated, and some data were converted into logarithms. The measured value, $\Delta T_{\text {rec }}, \Delta$ $\bar{T}_{\text {sk }}$, and $\% \mathrm{VO}_{2}$ were used for statistical analysis.

In terms of rectal and skin temperatures, data at 0 and $90 \mathrm{~min}$ of cold exposure were analyzed by paired $t$ test. Correlations between temperature decreases at the back of the hand $\left(\Delta T_{\mathrm{bh}}\right)$ and in the rectal temperature $\left(\Delta T_{\mathrm{re}}\right)$ compared with the respective baseline temperatures were analyzed using simple linear regression. Correlations between physical characteristics $\left(\mathrm{V} \cdot \mathrm{O}_{2 \max }\right.$ \% fat, lean body mass (LBM), BSA, and subcutaneous fat thickness) and $\% \mathrm{~V}^{-} \mathrm{O}_{2}, K_{\mathrm{b}}$, and $\% \mathrm{VC}$, as well as between $\% \mathrm{~V}$. $\mathrm{O}_{2}$ and \%VC at the end of exposure to cold, were also 
analyzed using simple linear regression. $P$ values below 0.05 were regarded as statistically significant.

\section{Results}

$T_{\text {re }}$ and temperatures at all skin locations reached a steady state after resting for $60 \mathrm{~min}$ in a thermo-neutral room. $T_{\text {re }}$ of the two participants remained higher after cold exposure compared with before exposure, whereas in the other subjects, $T_{\text {re }}$ decreased. All skin temperatures continuously decreased during cold exposure without stability. Shivering and/or goosebumps developed in all participants exposed to cold, and they reported feeling "very cold" thereafter.

Table 2 indicates the mean $\pm \mathrm{SD}$ of $T_{\text {re, }}, \bar{T}_{\text {sk }}$, all skin temperatures before and after cold exposure, and of changes in $T_{\text {re }}, \bar{T}_{\text {sk }}$, and all skin temperatures after cold exposure. The decreases in $T_{\text {re }}$ were $0.18 \pm 0.27^{\circ} \mathrm{C}$, which was not significant. Skin temperatures of each site and $\bar{T}_{\text {sk }}$ were significantly decreased by 90 -min cold exposure. The decreases in $\bar{T}_{\text {sk }}$ were $7.89 \pm 0.66^{\circ} \mathrm{C}$. Decreases in the forehead and abdominal (trunk region) skin temperatures were $5.32 \pm 1.15$ and $3.44 \pm 0.33{ }^{\circ} \mathrm{C}$, respectively, which were smaller than those at other sites of the skin. Skin temperature of the forearm, back of the hand, shin, and instep (peripheral sites) was markedly decreased by cold exposure, which was more than $10^{\circ} \mathrm{C}$ (Table 2).

Figure 2 shows the relationship between $\Delta T_{\mathrm{bh}}$ that declined the most among the skin sites and $\Delta T_{\text {re }}$. The correlation between $\Delta T_{\mathrm{bh}}$ and $\Delta T_{\mathrm{re}}$ was significantly negative $(r=-0.989, P<0.001)$ at the end of the cold exposure. The participants whose rectal temperatures remained higher in the cold had the lower skin temperatures at peripheral sites, such as the back of the hand.

Figure 3 shows the transmission images of near-infrared light through the fingers before and after cold exposure

Table 2 Rectal and skin temperatures before and after cold exposure for $90 \mathrm{~min}$

\begin{tabular}{lllll}
\hline Site & $0 \mathrm{~min}$ & $90 \mathrm{~min}$ & Change & $P$ value \\
\hline Rectal temperature & $37.01 \pm 0.24$ & $36.83 \pm 0.46$ & $0.18 \pm 0.27$ & 0.1794 \\
Skin temperature & & & & \\
$\quad$ Forehead & $35.04 \pm 0.23$ & $29.70 \pm 1.18$ & $5.32 \pm 1.15$ & $<0.0001$ \\
Abdomen & $35.23 \pm 0.65$ & $31.79 \pm 0.89$ & $3.44 \pm 0.33$ & $<0.0001$ \\
Forearm & $33.62 \pm 0.33$ & $20.58 \pm 1.97$ & $13.05 \pm 1.97$ & $<0.0001$ \\
Hand & $34.59 \pm 0.38$ & $18.43 \pm 1.08$ & $16.16 \pm 0.83$ & $<0.0001$ \\
Thigh & $34.55 \pm 0.86$ & $27.63 \pm 1.17$ & $6.92 \pm 1.15$ & $<0.0001$ \\
Shin & $34.18 \pm 0.42$ & $24.13 \pm 1.47$ & $10.05 \pm 1.40$ & $<0.0001$ \\
Instep & $33.88 \pm 0.83$ & $18.84 \pm 0.94$ & $15.03 \pm 0.68$ & $<0.0001$ \\
Mean $T_{\text {sk }}$ & $34.60 \pm 0.52$ & $26.71 \pm 0.93$ & $7.89 \pm 0.66$ & $<0.0001$ \\
\hline
\end{tabular}

Values are indicated as mean $\pm \mathrm{SD}$. Mean $T_{\text {sk }}$ shows mean skin temperature calculated using Hardy and DuBois formula. $P$ values were analyzed by paired $t$ test

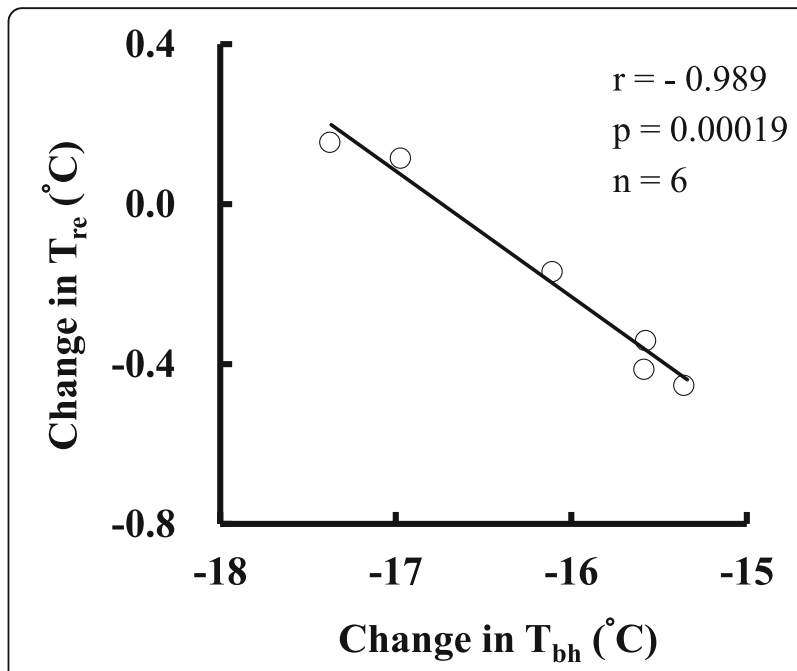

Fig. 2 Relationship between change in temperature of the skin on the back of the hand and change in rectal temperature after 90 min of cold exposure. $T_{\text {re }}$ and $T_{\text {bh }}$ indicate rectal and back of the hand temperatures, respectively

for $90 \mathrm{~min}$. The diameter of the blood vessels in all subjects was decreased by cold exposure for $90 \mathrm{~min}$ (baseline $7.5 \pm 1.6 \mathrm{~mm}, 90 \mathrm{~min} 5.2 \pm 1.7 \mathrm{~mm}, P<0.01$ ).

Figure 4 shows the relationships between $\mathrm{V} \cdot \mathrm{O}_{2 \max }$ and the \% change in $\mathrm{V} \mathrm{O}_{2}$ (Fig. $4 \mathrm{a}$ ), $K_{\mathrm{b}}$ (Fig. $4 \mathrm{~b}$ ), and the $\%$ VC (Fig. 4c) at 90 min during cold exposure. The correlation between $\mathrm{V} \cdot \mathrm{O}_{2 \max }$ and $\% \mathrm{~V} \cdot \mathrm{O}_{2}$ at 90 min cold exposure was significantly negative $(r=-0.916, P=0.004)$. Metabolic heat production in response to cold exposure increased less in a fitter than in a less-fit individual (Fig. 4a). The correlation between $\mathrm{V} \cdot \mathrm{O}_{2 \max }$ and $\mathrm{K}_{\mathrm{b}}$ at 90 min during cold exposure was not significant (Fig. 4b, $r=-0.283, P=0.586$ ). With respect to the degree of vasoconstriction, although $\mathrm{V} \cdot \mathrm{O}_{2 \max }$ and $\mathrm{DBV}$ did not correlate, $\mathrm{V} \cdot \mathrm{O}_{2 \max }$ and \%VC $(r=0.954, P=0.003)$ calculated from the change in DBV were significantly and positively correlated (Fig. 4c). Thus, the peripheral blood vessels were more constricted during cold exposure in fitter than in less-fit individuals.

Figure 5 shows the relationships between physical characteristics as \%fat, LBM, subcutaneous fat thickness, and BSA and $\ln \left[\% \mathrm{~V} \cdot \mathrm{O}_{2}\right]$ (four upper panels), $K_{\mathrm{b}}$ (four middle panels), and \%VC (four bottom panels) at 90 min of cold exposure. Physical characteristics (\%fat, LBM, BSA, and subcutaneous fat thickness) did not influence either metabolic heat production $\left(\% \mathrm{~V} \cdot \mathrm{O}_{2}\right)$ or peripheral vasoconstriction (\%VC). However, $K_{\mathrm{b}}$ was significantly affected by \%fat $(r=-0.936, P=0.006)$, LBM $(r=-0.857, P=0.029)$, BSA $(r=-0.836, P=0.038)$ and subcutaneous fat thickness $(r=-0.841, P=0.036)$.

Figure 6 shows the relationship between \%VC and logarithms of the increase in $\mathrm{V} \cdot \mathrm{O}_{2}$. There were negative relationships between $\% \mathrm{VC}$ and $\ln \left[\% \mathrm{~V} \cdot \mathrm{O}_{2}\right](r=-0.847$, 

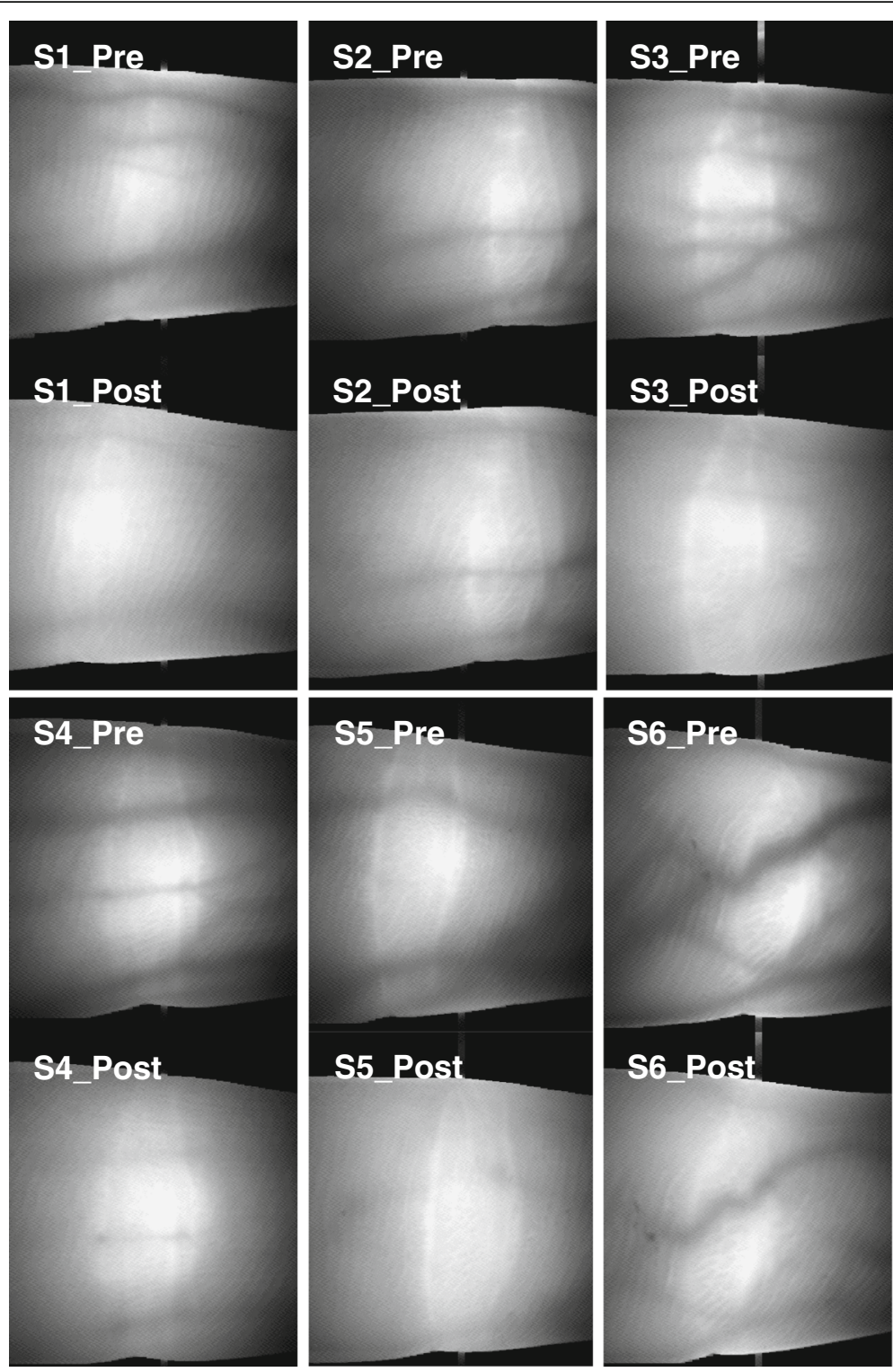

Fig. 3 Near-infrared transmission image of light in the fingers before and after exposure to cold for 90 min

$P=0.034)$. Metabolic heat production was not increased in participants whose peripheral blood vessels were more constricted during cold exposure. Instead, metabolic heat production was increased in those whose blood vessels were less constricted.

\section{Discussion}

This study found that (1) core temperature was better maintained in individuals with relatively low peripheral skin temperature, (2) vasoconstriction of the finger veins was more pronounced in individuals with higher maximum oxygen uptake than in others with lower maximum oxygen uptake, and that (3) metabolic heat production increased more from the baseline in individuals whose finger blood vessels were less constricted during cold exposure.

Peripheral vasoconstriction is important for thermoregulation in a cold environment, because the decrease in peripheral skin temperature, controlled by vasoconstriction, suppresses heat loss from the body surface and then the core temperature is better maintained. High ability of peripheral vasoconstriction enables the regulation of body temperature without the metabolic thermogenesis that is the second stage of the thermoregulation after the vasoconstriction.

Stromme and Hammel (1967) found that physically active rats produced more metabolic heat in a cold environment than inactive rats [32]. Bittel et al. (1988) also found a significant positive correlation between physical 


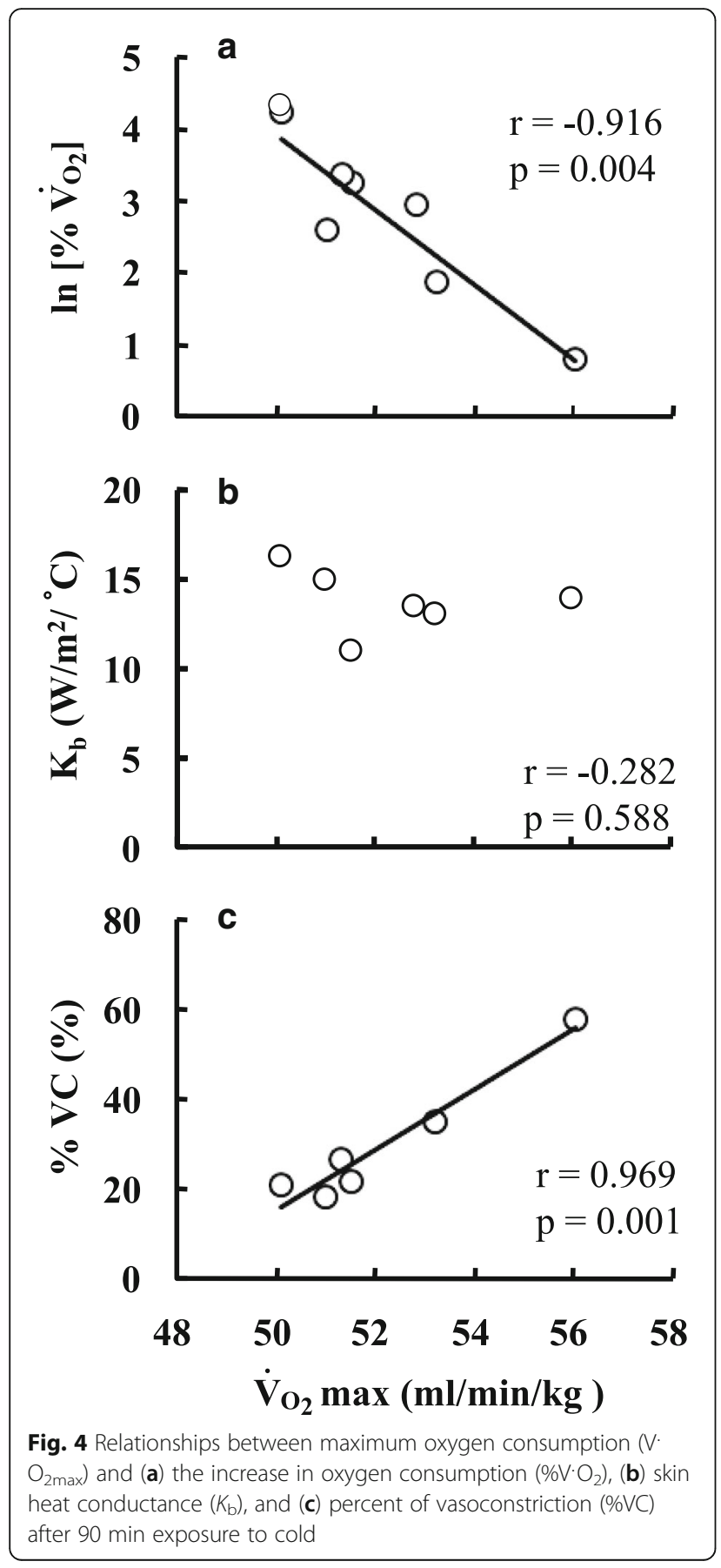

fitness and levels of metabolic heat production and skin heat conductance induced by acute exposure to cold at 1,5 , and $10{ }^{\circ} \mathrm{C}$ for $2 \mathrm{~h}$ in human [11]. These results showed that body temperature was not regulated only by suppression of heat loss caused by the vasoconstriction which was the first stage of thermoregulation; metabolic heat production which was the second stage occurred in not only inactive rat or lower fit person but also in active rat or higher fit person. It is thought that the increase of the metabolism to bring thermogenesis promotes movement of the heat to the skin, and then the heat loss increased. The results of the present study contradict these results in terms of metabolic heat production that negatively correlated with maximum oxygen uptake and skin heat conductance that did not correlate with maximum oxygen uptake. Maeda et al. (2007) indicated that metabolic heat production of individuals with a high basal metabolic rate, which was closely correlated with resting metabolic rate and muscle mass, was not increased during cold exposure because their core temperatures were only regulated by suppressing heat loss from the body surface [33]. The results of the present study might be influenced by not only the ability of vasoconstriction but also basal metabolic rate because it was though there was a relationship between maximum oxygen uptake and basal metabolic rate.

On the other hand, since individuals who are very fit also have more muscle mass, that is the main source of heat generation through shivering, the potential for heat production is high, and sufficient heat can be produced on demand to regulate core temperature. Accordingly, the present and previous results differ because the stages of thermoregulation were different. However, this raises the question of why the stages of the thermoregulation were different. Some explanations are that the actual living environment influences the acclimation of individuals, the contents of meals influence blood vessel compliance and/or heat production, and/or somatotype influences the ability to lose or generate heat. Body and subcutaneous fat might also be factors.

Bittel et al. (1988) indicated that the ratio of body fat significantly correlates with metabolic heat production and mean skin temperature [11]. In addition, Budd et al. (1991) also associated fat proportion with reduced heat production and heat loss, although physical fitness had no effect on heat production and heat loss during cold exposure [20]. However, Yoshida et al. (1998) reported that skin heat conductance was lower in the trained, than in untrained, individuals with the same body fat content [18]. The present study found that \%fat and subcutaneous fat thickness were negatively related to skin heat conductance but unrelated to metabolic heat production and vasoconstriction. Body fat, especially subcutaneous fat, plays a role in the suppression of heat loss from internal to external milieus. Therefore, the negative correlation between subcutaneous fat and $K_{\mathrm{b}}$, which is an index of heat loss, is reasonable, and the results of this study agreed with those of a previous investigation $[11,20]$. On the other hand, our findings of metabolic heat production did not agree with published results. Since an increase in metabolic heat production depends mainly on shivering of the muscle and not fat, body fat should not be related to metabolic heat generation. Previous results that have found a negative correlation 


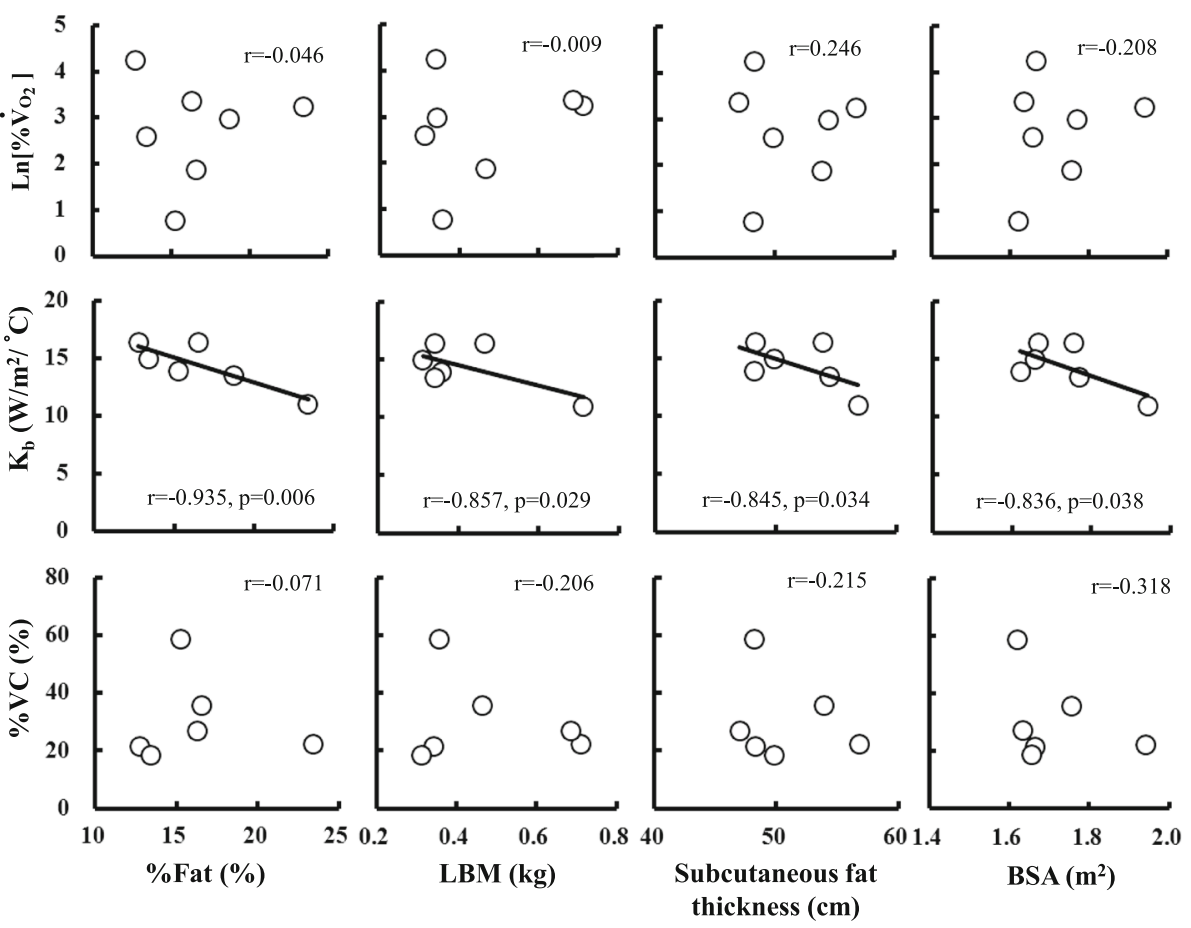

Fig. 5 Relationships between \%fat, lean body mass (LBM), subcutaneous fat thickness, body surface area (BSA), change in increasing rate of oxygen uptake $\left(\% \mathrm{~V} \cdot \mathrm{O}_{2}\right)$, skin heat conductance $\left(K_{\mathrm{b}}\right)$, and rate of vasoconstriction $(\% \mathrm{VC})$ after 90 min of cold exposure

between body fat and metabolic heat production might be caused by suppressing heat loss by body fat. However, these results might also include the influence of less ability of heat production, because persons with more fat might have less muscle, which would decrease metabolic heat production. In the present study, the body fat content and subcutaneous fat thickness were $16.6 \pm$ $3.60 \%$ and $0.50 \pm 0.17 \mathrm{~cm}$, respectively, values that were within the normal range for young adult Japanese males. So it was thought that the effect of body fat on cold-

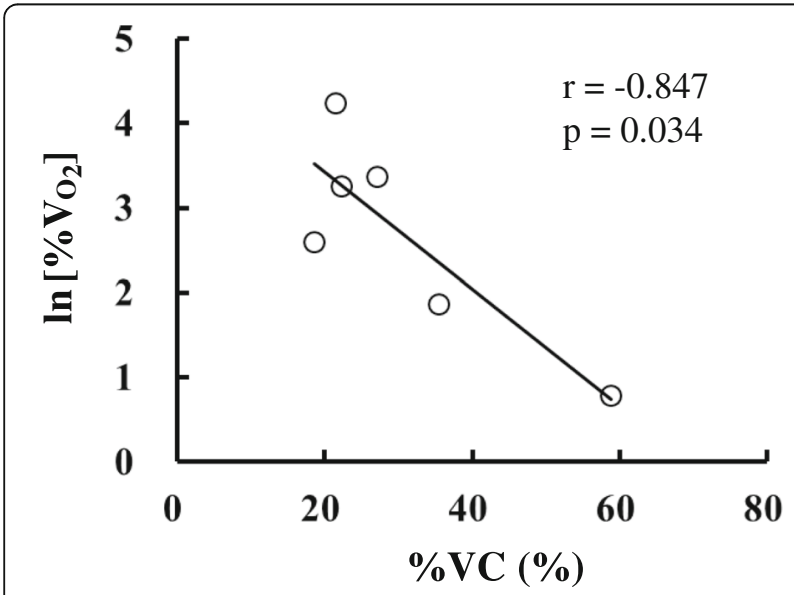

Fig. 6 Relationship between the rate of vasoconstriction (\%VC) and the increase in oxygen uptake $\left(\% \mathrm{~V} \cdot \mathrm{O}_{2}\right)$ induced metabolic heat production is very small in the present study which was the normal somatotype and narrow range of body fat variation of our study participants.

Most of the previous studies have estimated vasoconstriction under cold conditions only by measuring skin temperature at several sites, skin blood flow, and/or skin heat conductance, calculated using core, skin, and ambient temperatures. Here, we directly observed vasoconstriction in response to cold using near-infrared imaging of the finger blood vessels and found a significant positive correlation between maximum oxygen uptake and vasoconstriction. These results suggested that vasoconstriction ability is a sensitive index for evaluating cold tolerance.

The finding of greater vasoconstriction in fitter persons suggests increased sensitivity of the control of vasoconstriction to cold stimuli among such individuals. The mechanisms of physiological change-related thermoregulation associated with aerobic exercise are the improvements in compliance of the peripheral blood vessels [23-26], autonomic nervous function controlling the vasomotor system $[27,28]$, and vasomotor responses to thermal stimulation [34].

\section{Conclusion}

In conclusion, the present results suggested that the capacity for peripheral vasoconstriction is improved by 
physical exercise and that physical fitness is associated with enhanced ability to maintain metabolic heat production in a cold environment at resting metabolic levels of a thermoneutral condition. Fit individuals appear to have a greater capacity for vasoconstriction when exposed to cold and thus also appear to lose less heat than their less-fit counterparts.

\section{Abbreviations \\ \%DBV: Rate of change in diameter of the blood vessels; $\% \mathrm{~V} \cdot \mathrm{O}_{2}$ : Increase rate of oxygen consumption; $(R+C)$ : Radiant and convective heat exchange; $\Delta T_{\text {bh }}$ : Change in skin temperature at the back of the hand; BSA: Body surface area; DBV: Diameter of the blood vessels; $K_{\mathrm{b}}$ : Skin heat conductance; LBM: Lean body mass; $\mathrm{V} \cdot \mathrm{O}_{2}$ : Oxygen consumption; $\mathrm{V} \cdot \mathrm{O}_{2 \text { max }}$ : Maximum oxygen consumption; $\bar{T}_{\text {sk: }}$ : Mean skin temperature; $T_{\text {re: }}$ Rectal temperatures}

\section{Acknowledgements}

The author wishes to thank all the participants who participated in this study.

\section{Funding}

This work was supported by JSPS KAKENHI Grant Numbers JP16687010, JP26291097.

\section{Availability of data and materials}

All relevant data are within the paper.

\section{Author's contributions}

TM contributed to the conception and design of study, the experiment and data collection, statistical analysis and interpretation, and drafted the manuscript.

\section{Ethics approval and consent to participate}

This study was approved by the Research Ethics Committee of the Faculty of Design, at Kyushu University (No. 209). The purpose of the study and the procedures were explained to the subjects before they provided consent.

\section{Consent for publication}

Not applicable

\section{Competing interests}

The author declares that he/she has no competing interests.

\section{Publisher's Note}

Springer Nature remains neutral with regard to jurisdictional claims in published maps and institutional affiliations.

\section{Received: 5 March 2017 Accepted: 28 November 2017}

\section{Published online: 06 December 2017}

\section{References}

1. Baker PT. The Raymond Pearl Memorial Lecture, 1996: the eternal trianglegenes, phenotype, and environment. Am J Hum Biol. 1997;9:93-101.

2. Maeda T. Perspectives on environmental adaptability and physiological polymorphism in thermoregulation. J Physiol Anthropol Appl Hum Sci. 2005;24(3):237-40

3. Nishimura T, Motoi M, Egashira Y, Choi D, Aoyagi K, Watanuki S. Seasonal variation of non-shivering thermogenesis (NST) during mild cold exposure. J Physiol Anthropol. 2015;34:11.

4. Nakayama K, Iwamoto S. An adaptive variant of TRIB2, rs1057001, is associated with higher expression levels of thermogenic genes in human subcutaneous and visceral adipose tissues. J Physiol Anthropol. 2017:36(1):16

5. Ho CW, Beard JL, Farrell PA, Minson CT, Kenney WL. Age, fitness, and regional blood flow during exercise in the heat. J Appl Physiol. 1997; 82(4):1126-35

6. Martin WH 3rd, Ogawa T, Kohrt WM, Malley MT, Korte E, Kieffer PS, et al. Effects of aging, gender, and physical training on peripheral vascular function. Circulation. 1991;84(2):654-64.
7. Thomas CM, Pierzga JM, Kenney WL. Aerobic training and cutaneous vasodilation in young and older men. J Appl Physiol. 1999;86(5):1676-86.

8. Inoue $Y$, Havenith G, Kenney WL, Loomis JL, Buskirk ER. Exercise- and methylcholine-induced sweating responses in older and younger men: effect of heat acclimation and aerobic fitness. Int J Biometeorol. 1999; 42(4):210-6.

9. Andersen KL. Metabolic and circulatory aspects of tolerance to cold as affected by physical training. Fed Proc. 1966;25(4):1351-6.

10. Bittel J. The different types of general cold adaptation in man. Int J Sports Med. 1992;13(Suppl 1):S172-6.

11. Bittel JH, Nonotte-Varly C, Livecchi-Gonnot GH, Savourey GL, Hanniquet AM. Physical fitness and thermoregulatory reactions in a cold environment in men. J Appl Physiol. 1988;65(5):1984-9.

12. Falk B, Bar-Or O, Smolander J, Frost G. Response to rest and exercise in the cold: effects of age and aerobic fitness. J Appl Physiol. 1994;76(1):72-8.

13. Hirata K, Nagasaka T. Enhancement of calorigenic response to cold and to norepinephrine in physically trained rats. Jpn J Physiol. 1981;31(5):657-65.

14. Jacobs I, Romet T, Frim J, Hynes A. Effects of endurance fitness on responses to cold water immersion. Aviat Space Environ Med. 1984 55(8):715-20.

15. Kashimura O. Positive cross-adaptation between endurance physical training and general cold tolerance to acute cold exposure in rats. Nippon Seirigaku Zasshi. 1988:50(12):753-60.

16. Kollias J, Boileau R, Buskirk ER. Effects of physical conditioning in man on thermal responses to cold air. Int J Biometeorol. 1972;16(4):389-402.

17. Maeda T, Sugawara A, Fukushima T, Higuchi S, Ishibashi K. Effects of lifestyle, body composition, and physical fitness on cold tolerance in humans. J Physiol Anthropol Appl Hum Sci. 2005;24(4):439-43.

18. Yoshida T, Nagashima K, Nakai S, Yorimoto A, Kawabata T, Morimoto T. Nonshivering thermoregulatory responses in trained athletes: effects of physical fitness and body fat. Jpn J Physiol. 1998;48(2):143-8.

19. Young AJ, Sawka MN, Levine L, Burgoon PW, Latzka WA, Gonzalez RR, et al. Metabolic and thermal adaptations from endurance training in hot or cold water. J Appl Physiol. 1995;78(3):793-801.

20. Budd GM, Brotherhood JR, Hendrie AL, Jeffery SE. Effects of fitness, fatness, and age on men's responses to whole body cooling in air. J Appl Physiol. 1991;71(6):2387-93.

21. Daanen HA. Finger cold-induced vasodilation: a review. Eur J Appl Physiol. 2003;89(5):411-26

22. Kinoshita Y, Yamane T, Takubo T, Kanashima H, Kamitani T, Tatsumi N, et al. Measurement of hemoglobin concentrations using the astrim noninvasive blood vessel monitoring apparatus. Acta Haematol. 2002;108(2):109-10.

23. Kingwell BA, Arnold PJ, Jennings GL, Dart AM. The effects of voluntary running on cardiac mass and aortic compliance in Wistar-Kyoto and spontaneously hypertensive rats. J Hypertens. 1998;16(2):181-5.

24. Giannattasio C, Cattaneo BM, Mangoni AA, Carugo S, Sampieri L, Cuspidi C, et al. Changes in arterial compliance induced by physical training in hammer-throwers. J Hypertens Suppl. 1992;10(6):S53-5.

25. Franzoni F, Plantinga Y, Femia FR, Bartolomucci F, Gaudio C, Regoli F, et al. Plasma antioxidant activity and cutaneous microvascular endothelial function in athletes and sedentary controls. Biomed Pharmacother. 2004; 58(8):432-6

26. Cameron JD, Rajkumar C, Kingwell BA, Jennings GL, Dart AM. Higher systemic arterial compliance is associated with greater exercise time and lower blood pressure in a young older population. J Am Geriatr Soc. 1999; 47(6):653-6.

27. Ng AV, Callister R, Johnson DG, Seals DR. Endurance exercise training is associated with elevated basal sympathetic nerve activity in healthy older humans. J Appl Physiol. 1994;77(3):1366-74.

28. Nagai N, Hamada T, Kimura T, Moritani T. Moderate physical exercise increases cardiac autonomic nervous system activity in children with low heart rate variability. Childs Nerv Syst. 2004;20(4):209-14.

29. Hardy JD, Du Bois EF. The technic of measuring radiation and convection. J. Nutrition. 1937:15(5):461-75.

30. Budd GM, Brotherhood JR, Beasley FA, Hendrie AL, Jeffery SE, Lincoln GJ, et al. Effects of acclimatization to cold baths on men's responses to wholebody cooling in air. Eur J Appl Physiol Occup Physiol. 1993;67(5):438-49.

31. Colin J, Timbal J, Guieu JD, Boutelier C, Houdas Y. Combined effect of radiation and convection. In: Hardy JD, Gagge AP, Stolwijk JAJ, editors, Physiological and behavioral temperature regulation. Splingfield: Thomas; 1970. p. 81-96. 
32. Stromme SB, Hammel HT. Effects of physical training on tolerance to cold in rats. J Appl Physiol. 1967;23(6):815-24.

33. Maeda T, Fukushima T, Higuchi S, Ishibashi K. Involvement of basal metabolic rate on determining the type of cold tolerance. J Physio Anthropol. 2007;26(3):415-8.

34. Moriya K, Nakagawa K. Cold-induced vasodilatation of finger and maximal oxygen consumption of young female athletes born in Hokkaido. Int J Biometeorol. 1990;34(1):15-9.

Submit your next manuscript to BioMed Central and we will help you at every step:

- We accept pre-submission inquiries

- Our selector tool helps you to find the most relevant journal

- We provide round the clock customer support

- Convenient online submission

- Thorough peer review

- Inclusion in PubMed and all major indexing services

- Maximum visibility for your research

Submit your manuscript at www.biomedcentral.com/submit 